\title{
Metabolic Profiles, Bioactive Compounds, and Antioxidant Capacity in Lentinula edodes Cultivated on Log versus Sawdust Substrates
}

\author{
Miso Nam ${ }^{\dagger}$, Ji Yeon Choi ${ }^{\dagger}$ and Min-Sun Kim *
}

check for

updates

Citation: Nam, M.; Choi, J.Y.; Kim, M.-S. Metabolic Profiles, Bioactive Compounds, and Antioxidant Capacity in Lentinula edodes Cultivated on Log versus Sawdust Substrates. Biomolecules 2021, 11, 1654. https:// doi.org/10.3390/biom11111654

Academic Editor:

Elźbieta Skrzydlewska

Received: 6 October 2021

Accepted: 5 November 2021

Published: 8 November 2021

Publisher's Note: MDPI stays neutral with regard to jurisdictional claims in published maps and institutional affiliations.

Copyright: (c) 2021 by the authors. Licensee MDPI, Basel, Switzerland. This article is an open access article distributed under the terms and conditions of the Creative Commons Attribution (CC BY) license (https:// creativecommons.org/licenses/by/ $4.0 /)$.
Food Analysis Research Center, Korea Food Research Institute, Wanju 55365, Korea; msnam@kfri.re.kr (M.N.); jychoi@kfri.re.kr (J.Y.C.)

* Correspondence: mskim@kfri.re.kr; Tel.: +82-63-219-9460

+ These authors equally contributed to this work.

Abstract: Lentinula edodes (shiitake) is a popular nutritious edible mushroom with a desirable aroma and flavor. Traditional cultivation of L. edodes on beds of logs has been replaced by cultivation on sawdust, but the effects of cultivation changes on L. edodes mushrooms have not been well characterized. We determined the metabolic profile, bioactive compounds, and antioxidant capacity in L. edodes grown on log or sawdust substrates. Metabolic profiles of L. edodes extracts were determined by ${ }^{1} \mathrm{H}$ nuclear magnetic resonance (NMR) and ultra-performance liquid chromatography to quadrupole time-of-flight mass spectrometry. Principal component analysis score plots from ${ }^{1} \mathrm{H}$ NMR analysis showed clear differences between samples. Concentrations of primary metabolites, especially amino acids, generally decreased in L. edodes grown on logs compared to sawdust. Phenolic compounds showed variations in concentration depending on the cultivation method. Bioactive compounds and their antioxidant capacity were analyzed spectrophotometrically. L. edodes cultivated on logs had high concentrations of bioactive compounds with strong antioxidant capacity compared to L. edodes cultivated on sawdust. Thus, the concentration of primary metabolites was high in L. edodes grown on sawdust, which produces a high growth rate. In contrast, log-cultivated L. edodes, which were similar to wild mushrooms, had high levels of bioactive compounds and high antioxidant capacity. This information is useful for determining optimal cultivation conditions for nutritional and medicinal uses of L. edodes mushrooms.

Keywords: Lentinula edodes; metabolite profiling; bioactive compounds; antioxidant capacity; log bed cultivation; sawdust media cultivation

\section{Introduction}

The shiitake mushroom, Lentinula edodes, is nutritious and has a unique flavor that makes it the second most popular edible medicinal mushroom in the world [1]. It is widely cultivated in many Asian countries [2]. Production of L. edodes has increased faster than any other mushroom, accounting for about $25 \%$ of global edible fungus production $[3,4]$. L. edodes is valuable as food and medicine, rich in essential amino acids, dietary fiber, vitamins, and minerals but low in calories and fat [5-9]. Its bioactive compounds, including polysaccharides, terpenoids, steroids, phenols, nucleotides, and glycoprotein derivatives [10], may reduce the risk of hypertension, hypercholesterolemia, diabetes mellitus, and cancer [10,11].

L. edodes is manufactured under conditions similar to its natural environment on either synthetic sawdust substrates or hardwood logs, such as oak. Sawdust cultivation, which accounts for about $80 \%$ of the cultivation on substrates [12], reduces the cultivation period to a few months compared to two years using logs [13]. However, mushrooms grown on sawdust are considered inferior in flavor and nutrition to those cultivated on logs. Therefore, it is important to compare the biochemical composition and therapeutic effects 
of L. edodes grown on different substrates. While the proximate composition, free amino acids, and 5'-GMP concentrations for L. edodes cultivated on logs versus sawdust have been determined [13], the broader biochemical composition and biological activities of L. edodes mushrooms cultivated under different conditions have not been determined.

Here, we determined the metabolic profile, bioactive compounds, and antioxidant capacity of $L$. edodes cultivated on logs versus sawdust. The complementary use of nuclear magnetic resonance (NMR) and mass spectrometry (MS) provides excellent metabolic profiling by balancing the strengths and limitations inherent in each technique. We analyzed the most abundant primary metabolites of L. edodes extracts using ${ }^{1} \mathrm{H}$ NMR and the secondary metabolites using ultra-performance liquid chromatography to quadrupole time-of-flight mass spectrometry (UPLC-QTOF-MS). The bioactive compounds and their antioxidant capacity were determined spectrophotometrically. We characterized the differences in metabolites and estimated the bioactive compound and antioxidant capacity of L. edodes based on different cultivation conditions.

\section{Materials and Methods}

\subsection{Standards and Reagents}

Deuterated methanol (99.8 atom \% deuterium) and deuterium oxide (99.9 atom \% deuterium) were obtained from Cambridge Isotope Laboratories, Inc. (Andover, MA, USA). 3-(trimethylsilyl)propionic-2,2,3,3-d4 acid (TSP), Folin-Ciocalteu's phenol reagent, sodium carbonate, diethylene glycol, gallic acid, rutin, catechin, 2,2-diphenyl-1-picrylhydrazyl (DPPH), L-ascorbic acid, formic acid and hydrochloric acid were obtained from SigmaAldrich (St. Louis, MO, USA), and sodium hydroxide was purchased from Junsei Chemical (Tokyo, Japan). Methanol, water, and acetonitrile were of the highest commercial grade and obtained from Honeywell (St. Muskegon, MI, USA). All chemicals were of analytical grade.

\subsection{Mushroom Material}

L. edodes mushrooms were obtained commercially about $2 \mathrm{~kg}$ per each sample from local markets in South Korea. The L. edodes mushrooms were collected between April and May 2020. A total of 28 samples for L. edodes cultivated on log bed and 53 samples for L. edodes cultivated on sawdust media were collected. Detailed collection strains information is provided in Table S1. Fruiting bodies of mushrooms were chopped and freeze-dried as soon as they were collected. Dried fruiting bodies were ground to a fine powder and stored at $-80{ }^{\circ} \mathrm{C}$ until the experiment.

\subsection{Metabolite Profiling Using ${ }^{1} H$ NMR Analysis}

$500 \mu \mathrm{L}$ of methanol- $\mathrm{d}_{4}, 400 \mu \mathrm{L}$ of $0.2 \mathrm{M}$ sodium phosphate buffer in $\mathrm{D}_{2} \mathrm{O}(\mathrm{pH} 7.0 \pm 0.1)$, and $100 \mu \mathrm{L}$ of $6 \mathrm{mM}$ TSP were added to approximately $50 \mathrm{mg}$ of dried powder as extraction solvents. $\mathrm{D}_{2} \mathrm{O}$ was used as the internal lock signal and TSP was used as an internal standard with a chemical shift $(\delta)$ of $0.0 \mathrm{ppm}$. The mixtures were sonicated for $20 \mathrm{~min}$ and adjusted to $\mathrm{pH} 7.0 \pm 0.1$ using $0.2 \mathrm{M} \mathrm{NaOH}$ and $0.2 \mathrm{M} \mathrm{HCl}$ solutions. After centrifugation $(12,000 \mathrm{rpm}$, $20 \mathrm{~min}$, room temperature), the supernatants were transferred to $5 \mathrm{~mm}$ (ø) NMR tubes for NMR analysis. ${ }^{1} \mathrm{H}$ NMR spectra were acquired on a Bruker Avance III HD $800 \mathrm{MHz}$ FT-NMR Spectrometer (Bruker BioSpin Co., Billerica, MA, USA) at $298 \mathrm{~K}$ using a 5-mm triple-resonance inverse cryoprobe with Z-gradients. The 1D NOESY pulse sequence was applied to suppress the residual water signal. For each sample, 64 transients were collected into 64,000 data points using a spectral width of 16,393.4 with a relaxation delay of $2 \mathrm{~s}$ and an acquisition time of $2 \mathrm{~s}$. A $0.5 \mathrm{~Hz}$ line-broadening function was applied to all spectra for Fourier transformation, followed by phasing and baseline correction. Signal assignments for representative samples were achieved using 2D total correlation spectroscopy, $800 \mathrm{MHz}$ NMR database of Chenomx NMR Suite Version 8.6 (Edmonton, AB, Canada), and spiking experiments. The metabolites were quantified using the Chenomx NMR Suit Version 8.6. 


\subsection{UPLC-QTOF-MS Analysis}

The acquisition was performed using an Exion LC ${ }^{\mathrm{TM}}$ AD system coupled to a X500R QTOF system (all devices from AB SCIEX, Concord, ON, Canada), equipped with an electrospray ionization (ESI) source. The chromatographic separation analysis was carried out with an Acquity UPLC HSS T3 column $(2.1 \mathrm{~mm} \times 100 \mathrm{~mm}, 1.7 \mu \mathrm{m}$; Waters $)$ at $40{ }^{\circ} \mathrm{C}$; a binary gradient separation was performed at a flow rate of $0.45 \mathrm{~mL} / \mathrm{min}$. Mobile phase A consisted of $0.1 \%$ formic acid in water and mobile phase B consisted of $0.1 \%$ formic acid in acetonitrile. The linear gradient elution was as follows: $0-0.7 \mathrm{~min}, 1-5 \% \mathrm{~B} ; 0.7-2.7 \mathrm{~min}$, $5-25 \% \mathrm{~B} ; 2.7-4.5 \mathrm{~min}, 25-35 \% \mathrm{~B} ; 1 \mathrm{~min}$, isocratic $35 \% \mathrm{~B}$; $5.5-6.5 \mathrm{~min}, 35-45 \% \mathrm{~B} ; 1 \mathrm{~min}$, isocratic $45 \% \mathrm{~B} ; 7.5-8.5 \mathrm{~min}, 45-60 \% \mathrm{~B}$; 8.5-9.0 $\mathrm{min}, 60-100 \% \mathrm{~B}$; and $9.0-11 \mathrm{~min}$ (postacquisition time), $1 \% \mathrm{~B}$ to re-equilibrate the column. The total run-time for each injection was $13 \mathrm{~min}$ and the injection volume was $5 \mu \mathrm{L}$. The mass spectrometer was operated in positive and negative ionization modes and acquired data in the mass range from 50 to $1100 \mathrm{~m} / \mathrm{z}$. The following parameter settings were used: ion spray voltage: $5500 \mathrm{~V}$, temperature: $500^{\circ} \mathrm{C}$, curtain gas: $30 \mathrm{psi}$, declustering potential: $90 \mathrm{~V}$, and collision energy: $10 \mathrm{~V}$. An information dependent acquisition (IDA) method was used in which the five most intense mass peaks were fragmented. MS/MS experiments were run with a collision energy of $40 \mathrm{~V}$ and collision energy spread of $15 \mathrm{~V}$. Nitrogen was used as the drying, nebulizing, and collision gas.

\subsection{Preparation of the Methanolic Extract}

The methanol extraction step was performed following a method described by Barros et al. [14], slightly modified. Briefly, five grams of powdered mushrooms were extracted with $100 \mathrm{~mL}$ of methanol by shaking incubator (IST-3075R, Jeio Tech, Daejeon, Korea) at $25{ }^{\circ} \mathrm{C}$ at $200 \mathrm{rpm}$ for six h. The supernatant was filtered through filter paper (Whatman No.4). The residue was extracted again using the same method described earlier. The combined methanolic extracts were evaporated at $40{ }^{\circ} \mathrm{C}$ to dryness using a rotary vacuum evaporator (N-1300E, Eyela, Tokyo, Japan) and were weighed. Then, the obtained extracts were freeze-dried and re-dissolved in methanol at the concentration of $10 \mathrm{mg} / \mathrm{mL}$ for further use. The extraction yield was calculated according to the following formula: extraction yield $(\%)=$ methanolic extract weight after solvent evaporation/sample weight of freeze-dried mushroom $\times 100$.

\subsection{Determination of Bioactive Compounds}

The total phenolic content (TPC) was determined in accordance with colorimetric Folin-Ciocalteu assay with minor changes [15]. The absorbance $(760 \mathrm{~nm})$ was read in a multi-mode microplate reader. The phenolic content in the methanolic extract of $L$. edodes was calculated based on the calibration curve of gallic acid and expressed as milligram of gallic acid equivalents (GAE) per gram of dry methanolic extracts (D.E.).

The total flavonoid content (TFC) was performed according to the Davis method described by Huang et al. [16]. The absorbance was read at $420 \mathrm{~nm}$ in a spectrophotometer. The results were expressed using a calibration curve in $\mathrm{mg}$ of rutin equivalents (RE) per gram of dry methanolic extracts.

The tannin content was determined using a slightly modified vanillin- $\mathrm{HCl}$ method [17]. The absorbance was read at $500 \mathrm{~nm}$ in a spectrometer, and the results were expressed using a calibration curve in $\mathrm{mg}$ of catechin equivalents (CE) per gram of dry methanolic extracts.

The spectrophotometric measurements were performed by a multi-mode microplate reader (Synergy H1, BioTek Instruments, Winooski, VT, USA). 


\subsection{Determination of Antioxidant Capacity}

The DPPH free radical scavenging activity of the methanolic extract of L. edodes was carried out as described with some modification [15]. The absorbance was read at a wavelength of $517 \mathrm{~nm}$ using a spectrophotometer. The DPPH radical-scavenging activity (RSA) was calculated by the following equation: \% RSA $=$ [(Acontrol-Asample) $/$ Acontrol $] \times 100$, where Acontrol is the absorbance of the control and Asample is absorbance of the tested sample. The results were expressed in half-minimal inhibitory concentration $\left(\mathrm{IC}_{50}\right) \mathrm{calcu}-$ lated by comparing the RSA graph against the methanolic extract concentrations $(2,1,0.5$ 0.25 , and $0.125 \mathrm{mg} / \mathrm{mL}$ ).

The ABTS free radical scavenging activity was determined following the method modified by the authors [18], and the absorbance of the final reaction mixture was read at $734 \mathrm{~nm}$ against an appropriate blank. The ABTS RSA of the methanolic extract was calculated by the following equation: $\%$ RSA $=[1-$ Asample $/$ Acontrol $] \times 100$. The halfminimal inhibitory concentration $\left(\mathrm{IC}_{50}\right)$ was calculated from the graph of RSA percentage against the methanolic extract concentrations $(10,5,2.5,1.25$, and $0.625 \mathrm{mg} / \mathrm{mL})$.

The reducing antioxidant power was determined using the ferricyanide/Prussian blue method as described with slight modification [15]. The measurement of the absorbance was performed at $690 \mathrm{~nm}$ using a microplate reader. A higher absorbance indicates a robust reducing power. The extract concentration providing 0.5 of absorbance $\left(\mathrm{IC}_{50}\right)$ was calculated from the graph of absorbance against the methanolic extract concentrations $(10$, $5,2.5,1.25$, and $0.625 \mathrm{mg} / \mathrm{mL}$ ) of L. edodes.

\subsection{Statistical Analysis}

Extraction yield, bioactive compounds, and antioxidant capacity were performed in triplicate, and all data were presented as mean \pm standard deviations. The statistical significance of the data was analyzed by the Mann-Whitney U test using SPSS version 20.0 program (SPSS Inc., Chicago, IL, USA).

Multivariate statistical analyses were performed with a unit variance scale using SIMCA-P+ software, version 16.0 (Umetrics, Umeå, Sweden).

\section{Results and Discussion}

\subsection{Metabolite Profiling Using ${ }^{1} H N M R$}

To determine metabolic differences in the fruiting bodies of mushrooms cultivated on logs versus sawdust, we analyzed $L$. edodes extracts using ${ }^{1} \mathrm{H}$ NMR. Representative $800 \mathrm{MHz}{ }^{1} \mathrm{H}$ NMR spectra of L. edodes mushrooms grown on logs versus sawdust are shown in Figure 1.

The dominant signal in each ${ }^{1} \mathrm{H}$ NMR spectrum represents carbohydrates (3.0-4.5 ppm), and all samples regardless of culture conditions showed similar spectra suggesting similar metabolic profiles. However, further analysis showed that the amounts of many metabolites were distinctly different between the two groups. Spectral resonances of metabolites were assigned based on comparison with the chemical shifts of standard compounds using the $800 \mathrm{MHz}$ library from Chenomx NMR Suite Version 8.6, 2D NMR spectra (Figure S1), and spiking experiments. The analysis of L. edodes fruiting body extracts by ${ }^{1} \mathrm{H}$ NMR revealed 36 essential primary metabolites including amino acids, organic acids, and sugars that were quantified using the Chenomx NMR Suite (Table 1). 

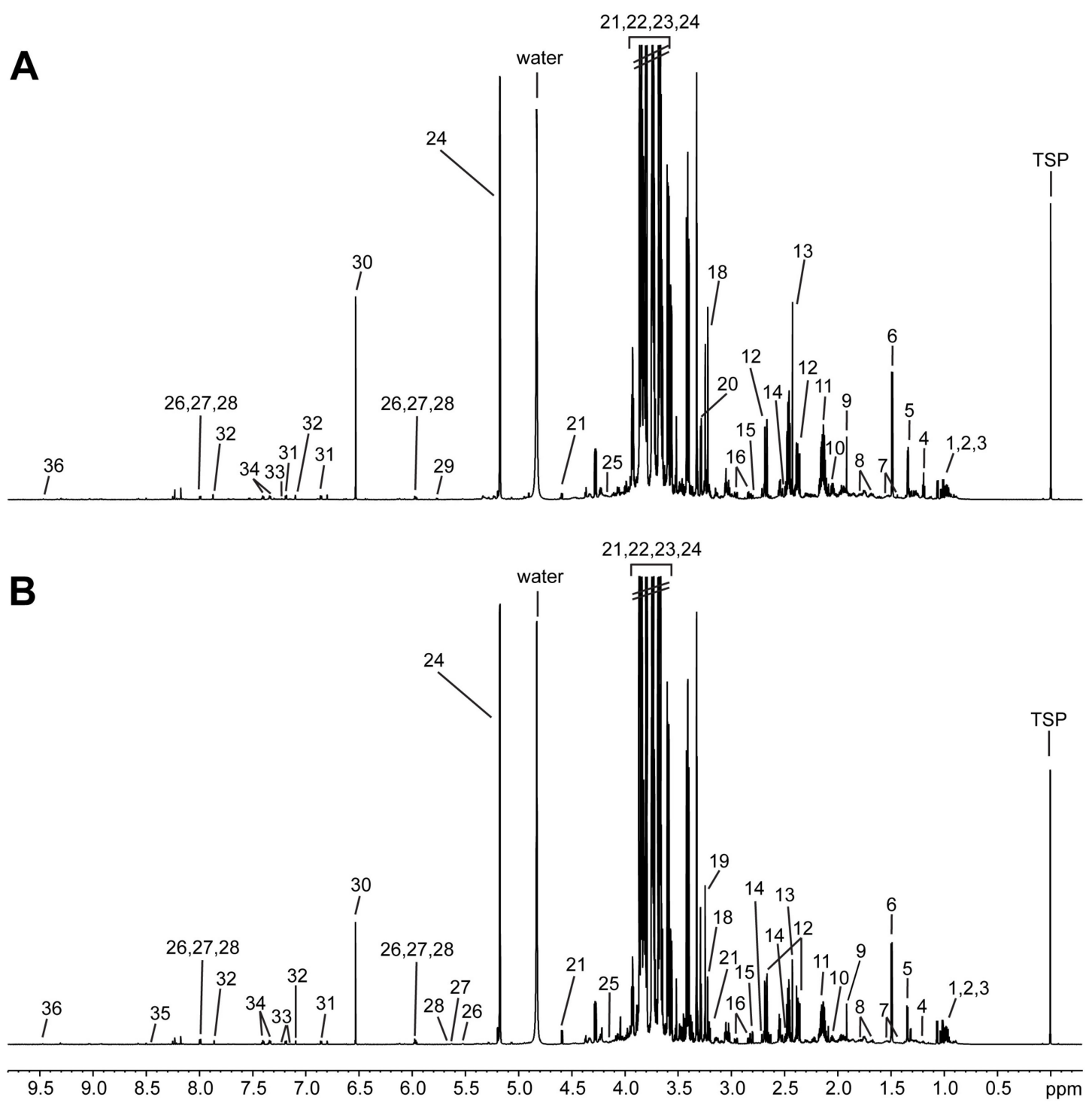

Figure 1. Representative ${ }^{1} \mathrm{H}$ NMR spectra of L. edodes extracts cultivated on (A) $\log$ bed and (B) sawdust media. (1, isoleucine; 2, leucine; 3, valine; 4, ethanol; 5, threonine; 6, alanine; 7, lysine; 8, arginine; 9, acetate; 10, glutamate; 11, glutamine; 12 , malate; 13 , succinate; 14 , citrate; 15 , aspartate; 16 , asparagine; 17 , ornithine; 18 , choline; 19 , sn-Glycero3-phosphocholine; 20, trimethylamine N-oxide; 21, glucose; 22, arbinitol; 23, mannitol; 24, trehalose; 25, myo-Inositol; 26, UDP-N-Acetylglucosamine; 27, UDP-glucose; 28, UDP-galactose; 29, uracil; 30, fumarate; 31, tyrosine; 32, histidine; 33 , tryptophan; 34 , phenylalanine; 35, formate; 36, NAD+). 
Table 1. Metabolites detected by ${ }^{1} \mathrm{H}$ NMR in Lentinula edodes extracts.

\begin{tabular}{|c|c|c|c|c|}
\hline \multirow[b]{2}{*}{ No. } & \multirow[b]{2}{*}{ Metabolite } & \multirow[b]{2}{*}{$\begin{array}{c}\log \text { Bed } \\
(\mu \mathrm{M}, \mathrm{n}=29)\end{array}$} & \multirow[b]{2}{*}{$\begin{array}{l}\text { Sawdust Media } \\
\quad(\mu \mathrm{M}, \mathrm{n}=52)\end{array}$} & \multirow{2}{*}{$\begin{array}{c}\text { x-Fold Change } \\
\text { Log Bed/Sawdust } \\
\text { Media }\end{array}$} \\
\hline & & & & \\
\hline 1 & Acetate & $397.88 \pm 693.76$ & $675.71 \pm 1225.33$ & 0.59 \\
\hline 2 & Formate & $6.44 \pm 2.25$ & $6.52 \pm 2.03$ & 0.99 \\
\hline 3 & Citrate & $527.57 \pm 211.06$ & $392.08 \pm 103.01$ & $1.35^{* *}$ \\
\hline 4 & Fumarate & $1024.32 \pm 252.79$ & $1112.18 \pm 225.77$ & 0.92 \\
\hline 5 & Malate & $4782.12 \pm 893.68$ & $5052.55 \pm 886.63$ & 0.95 \\
\hline 6 & Succinate & $365.91 \pm 181.96$ & $300.12 \pm 162.8$ & 1.22 \\
\hline 7 & Alanine & $1208.7 \pm 487.68$ & $1174.01 \pm 467.17$ & 1.03 \\
\hline 8 & Arginine & $442.31 \pm 226.7$ & $641.1 \pm 267.12$ & $0.69 * *$ \\
\hline 9 & Asparagine & $499.69 \pm 176.29$ & $588.61 \pm 187.99$ & $0.85 *$ \\
\hline 10 & Aspartate & $618.73 \pm 434.3$ & $707.73 \pm 407.19$ & 0.87 \\
\hline 11 & Glutamate & $1005.86 \pm 331.19$ & $1267.12 \pm 440.44$ & $0.79 * *$ \\
\hline 12 & Glutamine & $5447.25 \pm 1941.88$ & $6693.75 \pm 2364.08$ & $0.81 *$ \\
\hline 13 & Histidine & $162.39 \pm 56.05$ & $197.05 \pm 68.67$ & $0.82 *$ \\
\hline 14 & Isoleucine & $132.63 \pm 51.58$ & $225.35 \pm 102.73$ & $0.59 * * *$ \\
\hline 15 & Leucine & $189.6 \pm 68.7$ & $322.53 \pm 139.72$ & $0.59 * * *$ \\
\hline 16 & Lysine & $453.17 \pm 146.7$ & $729.61 \pm 217.9$ & $0.62 * * *$ \\
\hline 17 & Ornithine & $635.24 \pm 280.67$ & $1054.49 \pm 411.71$ & $0.60 * * *$ \\
\hline 18 & Phenylalanine & $88.08 \pm 25.01$ & $134.59 \pm 43.22$ & $0.65^{* * *}$ \\
\hline 19 & Threonine & $488.2 \pm 132.49$ & $655.21 \pm 176.73$ & $0.75^{* * *}$ \\
\hline 20 & Tryptophan & $35.15 \pm 15.18$ & $51.49 \pm 18.8$ & $0.68^{* * *}$ \\
\hline 21 & Tyrosine & $88.52 \pm 30.03$ & $173.57 \pm 86.12$ & $0.51 * * *$ \\
\hline 22 & Valine & $257.18 \pm 89.27$ & $442.15 \pm 179.74$ & $0.58^{* * *}$ \\
\hline 23 & Arabinitol & $11,832.42 \pm 5501.65$ & $11,989.78 \pm 5200.2$ & 0.99 \\
\hline 24 & Mannitol & $18,828.69 \pm 3851.1$ & $26,495.17 \pm 6170.15$ & $0.71^{* * *}$ \\
\hline 25 & Trehalose & $10,132.53 \pm 2783.68$ & $8688.03 \pm 3165.51$ & 1.17 \\
\hline 26 & Glucose & $463.2 \pm 753.62$ & $370.91 \pm 757.63$ & 1.25 \\
\hline 27 & myo-Inositol & $208.54 \pm 59.41$ & $258.13 \pm 149.75$ & 0.81 \\
\hline 28 & $\begin{array}{c}\text { UDP-N- } \\
\text { Acetylglucosamine }\end{array}$ & $63.28 \pm 11.53$ & $112.86 \pm 23.95$ & $0.56^{* * *}$ \\
\hline 29 & UDP-galactose & $19.8 \pm 3.5$ & $28.25 \pm 5.5$ & $0.70^{* * *}$ \\
\hline 30 & UDP-glucose & $63.16 \pm 11.03$ & $97.21 \pm 16.49$ & $0.65^{* * *}$ \\
\hline 31 & Ethanol & $186.21 \pm 270.16$ & $91.77 \pm 148.89$ & $2.03 *$ \\
\hline 32 & NAD+ & $35.23 \pm 5.38$ & $46.46 \pm 8.98$ & $0.76^{* * *}$ \\
\hline 33 & Uracil & $16.65 \pm 15.27$ & $11.78 \pm 12.73$ & 1.41 \\
\hline 34 & Choline & $504.11 \pm 231.99$ & $231.63 \pm 138.76$ & $2.18^{* * *}$ \\
\hline 35 & $\begin{array}{l}\text { sn-Glycero-3- } \\
\text { phosphocholine }\end{array}$ & $383.91 \pm 125.94$ & $816.89 \pm 310.72$ & $0.47^{* * *}$ \\
\hline 36 & $\begin{array}{l}\text { Trimethylamine } \\
\text { N-oxide }\end{array}$ & $183.94 \pm 37.73$ & $173.6 \pm 60.96$ & 1.06 \\
\hline
\end{tabular}

The results are presented as mean \pm SD. ${ }^{*} p<0.05,{ }^{* *} p<0.01$, and ${ }^{* * *} p<0.001$ indicate significant differences between samples cultivated on log bed and sawdust media.

This program uses the concentration of a known reference signal (in this case TSP) to determine the concentration of individual metabolites.

Principal components analysis (PCA) was performed on quantified metabolites of L. edodes mushroom extracts to identify primary metabolite variations that correlated with the cultivation method. PCA is an unsupervised clustering method requiring no prior knowledge of the data set that reduces the dimensionality of multivariate data while maintaining most of the variance [19]. The PCA score plot was established with four components and showed a clear separation between log-grown and sawdust-grown groups with high goodness-of-fit $\left(\mathrm{R}^{2}=0.644\right)$ and predictability $\left(\mathrm{Q}^{2}=0.432\right)$. The PCA score plot showed differences in metabolites along the first principal component (Figure 2) demonstrating that the cultivation method affects the primary metabolite content of $L$. edodes. 


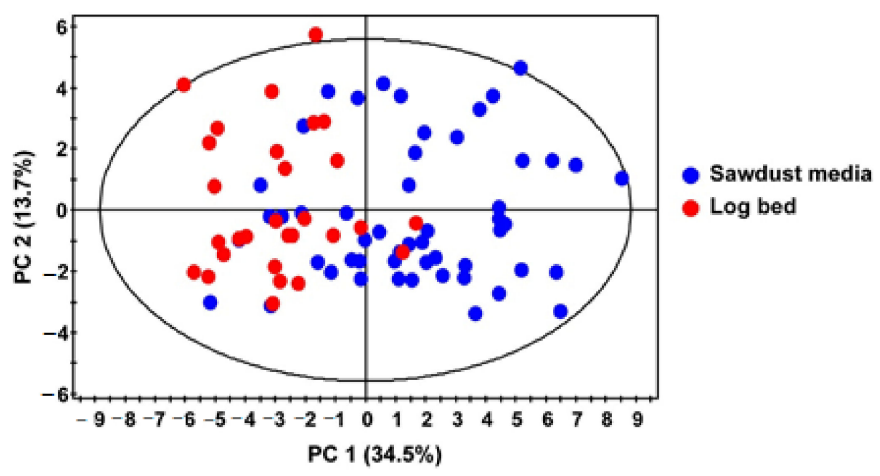

Figure 2. PCA score plot of quantified metabolites from ${ }^{1} \mathrm{H}$ NMR analysis in L. edodes extracts.

The Mann-Whitney $U$ test showed that 23 of the 36 identified metabolites had statistically significant differences in concentration between L. edodes mushrooms grown on different substrates. Overall, the primary metabolites that changed were significantly decreased in L. edodes grown on logs versus sawdust.

Most amino acids that showed significant differences in concentration had higher concentrations in L. edodes mushrooms grown on sawdust compared to logs, which was similar to the results of a previous study that measured total free amino acids [13]. Amino acids play a crucial role in cellular metabolism and protein synthesis, and mushrooms have proven to be good sources of almost all essential amino acids, comparable to common vegetables [5]. Amino acids are also the major umami component in L. edodes and are responsible for various physiological and pharmacological characteristics [20]. The amino acid content of mushrooms is related to maturity, quality grade, preservation methods, and post-harvest storage [21,22].

Malate was the major organic acid in L. edodes, which is consistent with previous results [23]. The only organic acid that showed a difference in concentration between the two groups was citrate, indicating that the cultivation environment of L. edodes had little or no effect on the concentration of organic acids.

Mannitol, trehalose, and arabinitol are the main soluble sugars in L. edodes [23,24], and our study found that these sugars were present at high concentrations in mushrooms grown on either substrate. Only mannitol showed a significant difference in concentration between the two groups with higher levels in L. edodes harvested from sawdust than from logs.

Nucleotide sugars are universal sugar donors that are important in the synthesis of polysaccharides, glycoproteins, proteoglycans, glycolipids, and glycosylated secondary metabolites [25]. We identified and quantified three nucleotide sugars (UDP-Nacetylglucosamine, UDP-glucose, and UDP-galactose) and determined that they were all present at lower concentrations in L. edodes grown on logs compared to those grown on sawdust.

\subsection{Metabolite Profiling Using UPLC-QTOF-MS}

Primary metabolites including amino acids, organic acids, and sugars were detected by ${ }^{1} \mathrm{H}$ NMR analysis of L. edodes extracts. However, secondary metabolites such as phenolic acids and flavonoids were not present in the ${ }^{1} \mathrm{H}$ NMR data; therefore, UPLC-QTOF-MS metabolic profiling was performed (Figure S2). Metabolites were identified based on their retention times, mass values, and MS/MS spectral data, and 17 metabolites were tentatively identified based on exact mass measurements of molecular ions and fragment ions (Table 2). 
Table 2. Metabolites detected by UPLC-QTOF-MS in Lentinula edodes extracts.

\begin{tabular}{|c|c|c|c|c|c|c|c|c|}
\hline \multirow[b]{2}{*}{ No. } & \multirow[b]{2}{*}{ Proposed Identity } & \multirow[b]{2}{*}{$\underset{(\mathrm{min})}{\mathrm{Rt}}$} & \multirow[b]{2}{*}{$\begin{array}{c}\text { Ionization } \\
\text { Mode }\end{array}$} & \multicolumn{2}{|c|}{ Precursor Ions $(\mathrm{m} / \mathrm{z})$} & \multirow[b]{2}{*}{$\begin{array}{l}\text { Difference } \\
\text { (ppm) }\end{array}$} & \multirow[b]{2}{*}{$\begin{array}{l}\text { Molecular } \\
\text { Formula }\end{array}$} & \multirow{2}{*}{$\begin{array}{c}\text { x-Fold Change } \\
\text { Log } \\
\text { Bed/Sawdust } \\
\text { Media }\end{array}$} \\
\hline & & & & Theoretical & Observed & & & \\
\hline 1 & 3,4-Dimethoxybenzoic acid & 3.69 & - & 181.0501 & 181.0502 & 0.64 & $\mathrm{C}_{9} \mathrm{H}_{10} \mathrm{O}_{4}$ & $1.24 * * *$ \\
\hline 2 & Apigenin & 6.8 & - & 269.045 & 269.0463 & 4.83 & $\mathrm{C}_{15} \mathrm{H}_{10} \mathrm{O}_{5}$ & $0.74^{*}$ \\
\hline 3 & Benzoic acid & 0.75 & - & 121.029 & 121.0284 & 4.59 & $\mathrm{C}_{7} \mathrm{H}_{6} \mathrm{O}_{2}$ & $3.17 * * *$ \\
\hline 4 & Caffeic acid & 3.86 & - & 179.0344 & 179.0344 & 0.2 & $\mathrm{C}_{9} \mathrm{H}_{8} \mathrm{O}_{4}$ & 0.33 \\
\hline 5 & Catechin & 3.27 & - & 289.0712 & 289.0718 & 2.02 & $\mathrm{C}_{15} \mathrm{H}_{14} \mathrm{O}_{6}$ & $7.2^{* *}$ \\
\hline 6 & Cinnamic acid & 5.72 & - & 147.0446 & 147.0446 & 0.03 & $\mathrm{C}_{9} \mathrm{H}_{8} \mathrm{O}_{2}$ & $1.31^{* * *}$ \\
\hline 7 & Coumaric acid & 4.35 & + & 165.0552 & 165.0538 & 8.3 & $\mathrm{C}_{9} \mathrm{H}_{8} \mathrm{O}_{3}$ & $0.15^{* * *}$ \\
\hline 8 & Ferulic acid & 4.59 & - & 193.0501 & 193.0517 & 8.37 & $\mathrm{C}_{10} \mathrm{H}_{10} \mathrm{O}_{4}$ & $0.40 *$ \\
\hline 9 & Gallic acid & 2.49 & - & 169.0137 & 169.012 & 10.06 & $\mathrm{C}_{7} \mathrm{H}_{6} \mathrm{O}_{5}$ & $1.06^{* * *}$ \\
\hline 10 & Glycitein & 5.58 & - & 283.0607 & 283.0608 & 0.53 & $\mathrm{C}_{16} \mathrm{H}_{12} \mathrm{O}_{5}$ & $0.09 * * *$ \\
\hline 11 & L-ascorbic acid & 0.81 & - & 175.0243 & 175.0225 & 10.08 & $\mathrm{C}_{6} \mathrm{H}_{8} \mathrm{O}_{6}$ & $0.23^{* * *}$ \\
\hline 12 & Niacinamide & 2 & + & 123.0558 & 123.0546 & 10.06 & $\mathrm{C}_{6} \mathrm{H}_{6} \mathrm{~N}_{2} \mathrm{O}$ & $0.14^{*}$ \\
\hline 13 & Riboflavin & 3.85 &,+- & 377.1461 & 377.1457 & 1.09 & $\mathrm{C}_{17} \mathrm{H}_{20} \mathrm{~N}_{4} \mathrm{O}_{6}$ & $4.28 * * *$ \\
\hline 14 & Salicylic acid & 4.5 & - & 137.0239 & 137.0228 & 7.81 & $\mathrm{C}_{7} \mathrm{H}_{6} \mathrm{O}_{3}$ & 2.92 \\
\hline 15 & Shikimic acid & 0.8 & - & 173.045 & 173.0433 & 9.82 & $\mathrm{C}_{7} \mathrm{H}_{10} \mathrm{O}_{5}$ & $1.10^{* * *}$ \\
\hline 16 & Syringic acid & 2.57 & - & 197.045 & 197.0449 & 0.51 & $\mathrm{C}_{9} \mathrm{H}_{10} \mathrm{O}_{5}$ & $1.34^{* * *}$ \\
\hline 17 & Vanillic acid & 3.44 & - & 167.0344 & 167.0349 & 2.78 & $\mathrm{C}_{8} \mathrm{H}_{8} \mathrm{O}_{4}$ & $0.34^{* *}$ \\
\hline
\end{tabular}

${ }^{*} p<0.05,{ }^{* *} p<0.01$, and ${ }^{* * *} p<0.001$ indicate significant differences between samples cultivated on log bed and sawdust media.

The concentrations of 15 metabolites, including phenolic compounds, were significantly different between the two mushroom groups based on the Mann-Whitney $U$ test. Phenolic compounds, which share an aromatic ring with one or more hydroxyl groups [26], are metabolites derived from secondary pathways in plants.

Cinnamic acid, which is in the phenylpropanoid pathway and has strong reactive oxygen scavenging activity [27], was increased in L. edodes cultivated on logs. Benzoic acid and its derivatives, including 3,4-dimethoxybenzoic acid, and syringic acid were also significantly higher in L. edodes cultivated on logs compared to sawdust, but vanillic acid concentrations were similar between the two groups. In contrast, coumaric acid and ferulic acid were higher in L. edodes grown on sawdust. These compounds have antioxidant, anti-inflammatory, and potential anticancer activities [28,29].

Catechin, known as an antioxidant with anticancer activity, was markedly increased in L. edodes cultivated on logs (Table 2) [30]. Apigenin and glycitein were significantly higher in L. edodes grown on sawdust. Apigenin, one of several natural flavones with many biological functions, is found in many plants. Riboflavin (vitamin B2) was significantly increased in L. edodes cultivated on logs. It is a micronutrient that is required for antibody production and for regulating human growth and reproduction. The levels of niacinamide (vitamin B complex) and ascorbic acid (vitamin C) were also higher in L. edodes grown on sawdust compared to growth on logs.

\subsection{Extraction Yield and Analysis of Bioactive Components}

There was no significant difference in yield for methanol extracts of samples grown on logs $(24.94 \%)$ compared to sawdust $(25.08 \%)$ (Table 3$)$. 
Table 3. Bioactive components of the methanolic extract in Lentinula edodes cultivated on log bed and sawdust media.

\begin{tabular}{cccc}
\hline & \multicolumn{3}{c}{ L. edodes } \\
\cline { 2 - 4 } Bioactive Compounds & $\begin{array}{c}\text { Log Bed } \\
(\mathbf{n}=\mathbf{2 9})\end{array}$ & $\begin{array}{c}\text { Sawdust Media } \\
\mathbf{( n = 5 2 )}\end{array}$ & p Value \\
\hline $\begin{array}{c}\text { Extraction yield (\%) } \\
\text { Total phenolic content }\end{array}$ & $24.94 \pm 4.48$ & $25.08 \pm 3.36$ & $0.420^{\mathrm{ns}}$ \\
$\begin{array}{c}\text { (mg GAE/g dry extract) } \\
\text { Total flavonoid content } \\
\text { (mg RE/g dry extract) } \\
\text { Total tannin content } \\
\text { (mg CE/g dry extract) }\end{array}$ & $5.06 \pm 0.62$ & $4.86 \pm 0.68$ & $0.017^{*}$ \\
\end{tabular}

The results are presented as mean \pm SD of triplicates. ${ }^{\text {ns }} p>0.05 ;{ }^{*} p<0.05$ and ${ }^{* * *} p<0.001$ indicate significant differences between samples cultivated on log bed and sawdust media.

Our results fell within the range for yield for commercial methanol extracts of $L$. edodes $(15.9-36.1 \%)$ [31-33].

Phenolic compounds are strongly correlated with the antioxidant capacity of plant materials [34]; therefore, we measured the TPC of mushroom extracts. The TPC for methanolic extracts of L. edodes grown on logs (5.06 mg GAE/g D.E.) was higher than for L. edodes grown on sawdust (4.86 $\mathrm{mg}$ GAE/g D.E.) indicating that the cultivation conditions influence the phenolic compound content of mushrooms. Wild mushrooms have higher levels of phenolic compounds than cultivated species [15,17,35]; thus, our results suggest that logs may provide an environment similar to the wild environment that supports the growth of L. edodes and that this environment could explain the higher phenol content.

Methanolic extracts of log-cultivated $L$. edodes had significantly higher TFC $(1.35 \pm 0.43 \mathrm{mg}$ RE/g D.E.) than the extract from sawdust-grown mushrooms $(1.20 \pm 0.53 \mathrm{mg} \mathrm{RE} / \mathrm{g}$ D.E.). Since flavonoids and phenolics contribute to the antioxidant effect of medicinal plants [36], L. edodes cultivated on logs with high flavonoid content would have more antioxidants than L. edodes cultivated on sawdust.

The tannin content in methanolic extracts of samples from both mushroom groups was low (0.62 mg CE/g D.E.) with no significant difference between the groups.

\subsection{Determination of Antioxidant Capacity}

The antioxidant capacity of methanolic extracts of L. edodes was determined using DPPH free radical scavenging, ABTS free radical scavenging, and the reducing power. The antioxidant capacity of $L$. edodes grown on logs versus sawdust was expressed as $\mathrm{IC}_{50}$ values (Table 4 ).

Table 4. $\mathrm{IC}_{50}(\mathrm{mg} / \mathrm{mL})$ properties of the methanolic extracts in Lentinula edodes cultivated on log bed and sawdust media.

\begin{tabular}{cccc}
\hline \multirow{2}{*}{ Assays } & \multicolumn{3}{c}{ L. edodes } \\
\cline { 2 - 4 } & $\begin{array}{c}\text { Log Bed } \\
(\mathbf{n}=\mathbf{2 9})\end{array}$ & $\begin{array}{c}\text { Sawdust Media } \\
\mathbf{( n = 5 2 )}\end{array}$ & $\boldsymbol{p}$ Value \\
\hline DPPH radical-scavenging activity & $0.88 \pm 0.17$ & $0.94 \pm 0.17$ & $0.012^{*}$ \\
ABTS radical-scavenging activity & $1.90 \pm 0.42$ & $2.38 \pm 0.61$ & $0.000^{* * *}$ \\
Reducing power activity & $2.33 \pm 0.58$ & $2.92 \pm 0.53$ & $0.000^{* * *}$
\end{tabular}

The results are presented as mean $\pm \mathrm{SD}(\mathrm{n}=3)$ of triplicates. ${ }^{*} p<0.05$ and ${ }^{* * *} p<0.001$ indicate significant differences between samples cultivated on log bed and sawdust media.

The free radical scavenging activity, based on the DPPH assay, for L. edodes cultivated on logs and sawdust, resulted in $\mathrm{IC}_{50}$ values of $0.88 \pm 0.17 \mathrm{mg} / \mathrm{mL}$ and $0.94 \pm 0.17 \mathrm{mg} / \mathrm{mL}$, respectively. These values were lower than the values reported for the inner cap, stipes, fruiting body of $L$. edodes $(0.169,0.213$, and $0.141 \mathrm{mg} / \mathrm{mL}$, respectively) [37] and sequential 
extracts of L. edodes $(0.15-0.17 \mathrm{mg} / \mathrm{mL})$ [38]. The RSA of the methanolic extracts using the ABTS assay was calculated as a percentage increase with the concentration. The L. edodes cultivated on logs showed greater activity $\left(\mathrm{IC}_{50}=1.90 \mathrm{mg} / \mathrm{mL}\right)$ compared to those cultivated on sawdust $\left(\mathrm{IC}_{50}=2.38 \mathrm{mg} / \mathrm{mL}\right)$. The reducing power was determined using the ferricyanide/Prussian blue assay based on the reduction of ferric iron [17]. The $\mathrm{IC}_{50}$ values based on the reducing ability of methanolic extracts of $L$. edodes cultivated on logs or sawdust ( 2.33 and $2.92 \mathrm{mg} / \mathrm{mL}$, respectively) were similar to a previous report for mushrooms grown in a solid medium $(2.26 \mathrm{mg} / \mathrm{mL})$ [39].

L. edodes cultivated on logs had higher free radical scavenging activity than L. edodes grown on sawdust. Similarly, the TPC and TFC in mushrooms grown on logs were higher than for mushrooms grown on sawdust. Thus, higher antioxidant capacity correlated well with greater total phenolics and flavonoids, and our results were similar.

\section{Conclusions}

This study is the first to report the metabolic profile, bioactive compounds, and antioxidant capacity of $L$. edodes fruiting bodies produced on logs versus sawdust substrates. Metabolic profiling using ${ }^{1} \mathrm{H}$ NMR and UPLC-QTOF-MS analysis revealed that the concentration of primary and secondary metabolites in L. edodes mushrooms was significantly different in L. edodes grown on different substrates. Most of the primary metabolites were present at higher concentrations in L. edodes cultivated on sawdust, which may be the result of greater primary metabolism due to the faster growth of $L$. edodes cultivated on sawdust compared to logs. In contrast, L. edodes cultivated on logs had increased bioactive compounds and antioxidant capacity compared to sawdust, and growth on logs was associated with higher concentrations of TPC and TFC. Further experiments in vitro and in vivo will be needed to determine the possible benefits of an increased antioxidant content in L. edodes. Our results provide information on key differences between log and sawdust cultivation for $L$. edodes that can be used to decide which method is advantageous for improving the nutritional and/or medicinal benefits of L. edodes mushrooms.

Supplementary Materials: The following are available online at https://www.mdpi.com/article/ 10.3390/biom11111654/s1, Figure S1: Expansion of representative 2D NMR spectra (TOCSY) of L. edodes extracts, Figure S2: The spectra of UPLC-QTOF-MS from L. edodes extracts, Table S1: Sample list of Lentinula edodes.

Author Contributions: M.N.: Conceptualization, methodology, formal analysis, investigation, data curation, writing —original draft, visualization. J.Y.C.: Methodology, formal analysis, investigation, data curation, writing-original draft. M.-S.K.: Conceptualization, investigation, visualization, writing —original draft, review \& editing, supervision, funding acquisition. All authors have read and agreed to the published version of the manuscript.

Funding: This study was carried out with the support of the 'R\&D Program for Forest Science Technology (Project No. 2020207A00-2122-BA01)' provided by the Korea Forest Service (Korea Forestry Promotion Institute).

Conflicts of Interest: The authors declare no conflict of interest.

\section{References}

1. Miles, P.G.; Chang, S.-T. Mushrooms: Cultivation, Nutritional Value, Medicinal Effect, and Environmental Impact; CRC Press: Boca Raton, FL, USA, 2004.

2. Chen, L.; Gong, Y.; Cai, Y.; Liu, W.; Zhou, Y.; Xiao, Y.; Xu, Z.; Liu, Y.; Lei, X.; Wang, G. Genome sequence of the edible cultivated mushroom Lentinula edodes (Shiitake) reveals insights into lignocellulose degradation. PLoS ONE 2016, 11, e0160336. [CrossRef] [PubMed]

3. Tian, Y.; Zhao, Y.; Huang, J.; Zeng, H.; Zheng, B. Effects of different drying methods on the product quality and volatile compounds of whole shiitake mushrooms. Food Chem. 2016, 197, 714-722. [CrossRef]

4. Boa, E.R. Wild Edible Fungi: A Global Overview of Their Use and Importance to People; FAO: Rome, Italy, $2004 ;$ p. 163.

5. Mattila, P.; Salo-Väänänen, P.; Könkö, K.; Aro, H.; Jalava, T. Basic composition and amino acid contents of mushrooms cultivated in Finland. J. Agric. Food Chem. 2002, 50, 6419-6422. [CrossRef] 
6. Fukushima, M.; Ohashi, T.; Fujiwara, Y.; Sonoyama, K.; Nakano, M. Cholesterol-lowering effects of maitake (Grifola frondosa) fiber, shiitake (Lentinus edodes) fiber, and enokitake (Flammulina velutipes) fiber in rats. Exp. Biol. Med. 2001, 226, 758-765. [CrossRef] [PubMed]

7. Morales, D.; Gil-Ramirez, A.; Smiderle, F.R.; Piris, A.J.; Ruiz-Rodriguez, A.; Soler-Rivas, C. Vitamin D-enriched extracts obtained from shiitake mushrooms (Lentinula edodes) by supercritical fluid extraction and UV-irradiation. Innov. Food Sci. Emerg. Technol. 2017, 41, 330-336. [CrossRef]

8. Xue, Z.; Chen, Y.; Jia, Y.; Wang, Y.; Lu, Y.; Chen, H.; Zhang, M. Structure, thermal and rheological properties of different soluble dietary fiber fractions from mushroom Lentinula edodes (Berk.) Pegler residues. Food Hydrocoll. 2019, 95, 10-18. [CrossRef]

9. Carneiro, A.A.; Ferreira, I.C.; Dueñas, M.; Barros, L.; Da Silva, R.; Gomes, E.; Santos-Buelga, C. Chemical composition and antioxidant activity of dried powder formulations of Agaricus blazei and Lentinus edodes. Food Chem. 2013, 138, $2168-2173$. [CrossRef] [PubMed]

10. Soković, M.; Ćirić, A.; Glamočlija, J.; Stojković, D. The bioactive properties of mushrooms. Wild Plants Mushrooms Nuts Funct. Food Prop. Appl. 2017, 4, 83-122.

11. Zhuang, H.; Chen, Z.; Feng, T.; Yang, Y.; Zhang, J.; Liu, G.; Li, Z.; Ye, R. Characterization of Lentinus edodes $\beta$-glucan influencing the in vitro starch digestibility of wheat starch gel. Food Chem. 2017, 224, 294-301. [CrossRef]

12. Pire, D.; Wright, J.; Albertó, E. Cultivation of shiitake using sawdust from widely available local woods in Argentina. Micol. Apl. Int. 2001, 13, 87-91.

13. Tabata, T.; Tomioka, K.; Iwasaka, Y.; Shinohara, H.; Ogura, T. Comparison of chemical compositions of shiitake (Lentinus edodes (Berk.) Sing) cultivated on logs and sawdust substrate. Food Sci. Technol. Res. 2006, 12, 252-255. [CrossRef]

14. Barros, L.; Calhelha, R.C.; Vaz, J.A.; Ferreira, I.C.; Baptista, P.; Estevinho, L.M. Antimicrobial activity and bioactive compounds of Portuguese wild edible mushrooms methanolic extracts. Eur. Food Res. Technol. 2007, 225, 151-156. [CrossRef]

15. Woldegiorgis, A.Z.; Abate, D.; Haki, G.D.; Ziegler, G.R. Antioxidant property of edible mushrooms collected from Ethiopia. Food Chem. 2014, 157, 30-36. [CrossRef]

16. Huang, R.; Wu, W.; Shen, S.; Fan, J.; Chang, Y.; Chen, S.; Ye, X. Evaluation of colorimetric methods for quantification of citrus flavonoids to avoid misuse. Anal. Methods 2018, 10, 2575-2587. [CrossRef]

17. Erbiai, E.H.; da Silva, L.P.; Saidi, R.; Lamrani, Z.; Esteves da Silva, J.C.; Maouni, A. Chemical Composition, Bioactive Compounds, and Antioxidant Activity of Two Wild Edible Mushrooms Armillaria mellea and Macrolepiota procera from Two Countries (Morocco and Portugal). Biomolecules 2021, 11, 575. [CrossRef] [PubMed]

18. Hu, Y.-N.; Sung, T.-J.; Chou, C.-H.; Liu, K.-L.; Hsieh, L.-P.; Hsieh, C.-W. Characterization and antioxidant activities of yellow strain Flammulina velutipes (Jinhua mushroom) polysaccharides and their effects on ROS content in L929 cell. Antioxidants 2019, 8, 298. [CrossRef] [PubMed]

19. Worley, B.; Halouska, S.; Powers, R. Utilities for quantifying separation in PCA/PLS-DA scores plots. Anal. Biochem. 2013, 433, 102-104. [CrossRef] [PubMed]

20. Dong, M.; Qin, L.; Xue, J.; Du, M.; Lin, S.-Y.; Xu, X.-B.; Zhu, B.-W. Simultaneous quantification of free amino acids and 5'-nucleotides in shiitake mushrooms by stable isotope labeling-LC-MS/MS analysis. Food Chem. 2018, 268, 57-65. [CrossRef] [PubMed]

21. Manninen, H.; Rotola-Pukkila, M.; Aisala, H.; Hopia, A.; Laaksonen, T. Free amino acids and $5^{\prime}$-nucleotides in Finnish forest mushrooms. Food Chem. 2018, 247, 23-28. [CrossRef] [PubMed]

22. Ming, T.; Li, J.; Huo, P.; Wei, Y.; Chen, X. Analysis of free amino acids in Russula griseocarnosa harvested at different stages of maturity using iTRAQ ${ }^{\circledR}$-LC-MS/MS. Food Anal. Methods 2014, 7, 1816-1823. [CrossRef]

23. Gao, S.; Huang, Z.; Feng, X.; Bian, Y.; Huang, W.; Liu, Y. Bioconversion of rice straw agro-residues by Lentinula edodes and evaluation of non-volatile taste compounds in mushrooms. Sci. Rep. 2020, 10, 1814. [CrossRef]

24. Li, W.; Chen, W.; Yang, Y.; Zhang, J.; Feng, J.; Yu, H.; Zhou, S.; Li, X.; Liu, Y. Effects of culture substrates on taste component content and taste quality of Lentinula edodes. Int. J. Food Sci. Technol. 2017, 52, 981-991. [CrossRef]

25. Bar-Peled, M.; O'Neill, M.A. Plant nucleotide sugar formation, interconversion, and salvage by sugar recycling. Annu. Rev. Plant Biol. 2011, 62, 127-155. [CrossRef] [PubMed]

26. Russell, W.; Duthie, G. Plant secondary metabolites and gut health: The case for phenolic acids. Proc. Nutr. Soc. 2011, 70, 389-396. [CrossRef]

27. Pontiki, E.; Hadjipavlou-Litina, D.; Litinas, K.; Geromichalos, G. Novel cinnamic acid derivatives as antioxidant and anticancer agents: Design, synthesis and modeling studies. Molecules 2014, 19, 9655-9674. [CrossRef]

28. Pei, K.; Ou, J.; Huang, J.; Ou, S. p-Coumaric acid and its conjugates: Dietary sources, pharmacokinetic properties and biological activities. J. Sci. Food Agric. 2016, 96, 2952-2962. [CrossRef] [PubMed]

29. Zduńska, K.; Dana, A.; Kolodziejczak, A.; Rotsztejn, H. Antioxidant properties of ferulic acid and its possible application. Ski. Pharmacol. Physiol. 2018, 31, 332-336. [CrossRef] [PubMed]

30. Musial, C.; Kuban-Jankowska, A.; Gorska-Ponikowska, M. Beneficial properties of green tea catechins. Int. J. Mol. Sci. 2020, 21, 1744. [CrossRef] [PubMed]

31. Yang, J.-H.; Lin, H.-C.; Mau, J.-L. Antioxidant properties of several commercial mushrooms. Food Chem. 2002, 77, 229-235. [CrossRef] 
32. Cheung, L.; Cheung, P.C. Mushroom extracts with antioxidant activity against lipid peroxidation. Food Chem. 2005, 89, 403-409. [CrossRef]

33. Cheung, L.; Cheung, P.C.; Ooi, V.E. Antioxidant activity and total phenolics of edible mushroom extracts. Food Chem. 2003, 81, 249-255. [CrossRef]

34. Velioglu, Y.; Mazza, G.; Gao, L.; Oomah, B. Antioxidant activity and total phenolics in selected fruits, vegetables, and grain products. J. Agric. Food Chem. 1998, 46, 4113-4117. [CrossRef]

35. Alkin, M.; Söğüt, E.; Seydim, A.C. Determination of bioactive properties of different edible mushrooms from Turkey. J. Food Meas. Charact. 2021, 15, 3608-3617. [CrossRef]

36. Kaur, S.; Mondal, P. Study of total phenolic and flavonoid content, antioxidant activity and antimicrobial properties of medicinal plants. J. Microbiol. Exp. 2014, 1, 00005. [CrossRef]

37. Krüzselyi, D.; Móricz, Á.M.; Vetter, J. Comparison of different morphological mushroom parts based on the antioxidant activity. LWT 2020, 127, 109436. [CrossRef]

38. Morales, D.; Piris, A.J.; Ruiz-Rodriguez, A.; Prodanov, M.; Soler-Rivas, C. Extraction of bioactive compounds against cardiovascular diseases from Lentinula edodes using a sequential extraction method. Biotechnol. Prog. 2018, 34, 746-755. [CrossRef] [PubMed]

39. Reis, F.S.; Martins, A.; Barros, L.; Ferreira, I.C. Antioxidant properties and phenolic profile of the most widely appreciated cultivated mushrooms: A comparative study between in vivo and in vitro samples. Food Chem. Toxicol. 2012, 50, 1201-1207. [CrossRef] 